\title{
Tegaserod Does not Alter Fasting or Meal-Induced Biliary Tract Motility
}

Robert S. Fisher, M.D., Johnson Thistle, M.D., Anthony Lembo, M.D., James Novick, M.D., Patrick O’Kane, M.D., William D. Chey, M.D., Christoph Beglinger, M.D., Peter Rueegg, M.D., Victor Shi, M.D., Angeli Dogra, B.S., Dongham Luo, Ph.D., and David L. Earnest, M.D.

Temple University Hospital, Philadelphia; Mayo Clinic, Rochester; Beth Israel Deaconess Hospital, Boston; Charm City Research, Baltimore; Thomas Jefferson University Hospital, Philadelphia; University of Michigan Health Service, Ann Arbor; University Hospital, Basel, Switzerland; Novartis Pharma AG, Basel, Switzerland; and Novartis Pharmaceuticals Corporation, East Hanover, New Jersey

OBJECTIVE: $\quad$ Tegaserod is a $5-\mathrm{HT}_{4}$ receptor partial agonist that increases peristaltic activity of the intestinal tract. It is approved for the treatment of patients with irritable bowel syndrome with constipation (IBS-C). IBS is a chronic gastrointestinal disorder of function that is reported to be associated with an increased incidence of abdominal surgery including cholecystectomy. The effect of tegaserod on nongut digestive organs, such as the gallbladder and biliary tract, has not been previously investigated. Therefore, this study aimed to evaluate the effects of tegaserod on gallbladder contractility and on functional status of the sphincter of Oddi during both the interdigestive and the digestive periods in healthy female subjects and in female patients with IBS-C.

METHODS: $\quad$ During a 6-wk, double-blind, placebo-controlled crossover study, gallbladder contractility and concomitant change in luminal diameter of the common hepatic duct (CHD) and the common bile duct (CBD, both proximal and distal) in response to a standard liquid meal were quantified using real-time ultrasonography. Changes in luminal diameter of the CHD and the CBD were used as a surrogate marker for sphincter of Oddi function. Ultrasound measurements were conducted every $15 \mathrm{~min}$ from $45 \mathrm{~min}$ before, to $60 \mathrm{~min}$ after the test meal to observe the impact of tegaserod on gallbladder volume and any concomitant change in the diameters of the CHD and the CBD that developed in response to gallbladder contraction. The ultrasound measurements of gallbladder contractility, along with the CHD and the CBD diameters, were repeated after each of the two 2-wk periods of treatment with tegaserod or placebo. The recommended dose of tegaserod (6 mg b.i.d.) for IBS-C patients was used in healthy female subjects $(n=13)$ and female patients with IBS-C $(n=$ 20). Twice this dose (12 $\mathrm{mg}$ b.i.d.) was also evaluated in an additional 20 female patients with IBS-C. Statistical evaluations were conducted using a two-sided analysis of variance (ANOVA).

RESULTS: Gallbladder contractility variables including ejection fraction, ejection rate and ejection period, fasting and residual volume, and maximal emptying, were similar after 2 wk of treatment with tegaserod $6 \mathrm{mg}$ b.i.d. and placebo in healthy female subjects and female patients with IBS-C. There were no significant changes in the luminal diameters of the CHD or the CBD after tegaserod compared to placebo in any cohort. Additionally, no significant dilation ( $\geq 7 \mathrm{~mm}$ in diameter) of the CHD or CBD was observed during maximal gallbladder emptying. Similar results were also observed when tegaserod was given at $12 \mathrm{mg}$ b.i.d. in patients with IBS-C. Tegaserod treatment had no significant effect on plasma CCK concentration in response to the test meal. No significant abdominal pain or unexpected adverse events were reported during the study.

CONCLUSIONS: This study showed no significant pharmacodynamic effect of tegaserod on gallbladder contractility or on CBD and CHD diameters as a surrogate marker of sphincter of Oddi function during both the interdigestive (fasting) and the digestive (postprandial) periods in healthy female subjects and female patients with IBS-C.

\section{INTRODUCTION}

Tegaserod is a selective $5-\mathrm{HT}_{4}$ receptor partial agonist that has a promotile effect on the stomach, small intestine, and colon in animals and humans. This effect results from enhanced peristalsis leading to augmented aboral luminal trans- port of intestinal contents (1-3). Tegaserod was recently approved for the treatment of patients with symptomatic irritable bowel syndrome with constipation (IBS-C). IBS is a gastrointestinal disorder of function reported to be associated with an increased risk of abdominal surgery including cholecystectomy (4). Since the cause of this increased risk 
remains largely unknown, and tegaserod affects motility of other parts of the GI tract, the potential impact of tegaserod on gallbladder and biliary tract motility in IBS patients is a matter of interest.

A complex interaction of hormones and neuropeptides regulates normal gallbladder and biliary tract function. Gastrointestinal peptides such as CCK, pancreatic polypeptide, and motilin mediate postprandial gallbladder contraction (5). A drug may alter gallbladder motility by acting directly on nerves, receptors, or muscle in the gallbladder or biliary tract, or by modifying the plasma concentration of peptides that modulate gallbladder or biliary motility. For example, erythromycin causes gallbladder contraction through direct stimulation of motilin receptors $(6,7)$. The gallbladder expresses $\alpha$-, $\beta_{1-}$, and $\beta_{3}$-adrenergic receptors (8). Treatment with the postsynaptic $\alpha_{1}$-antagonist indoramin enhances postprandial gallbladder emptying in humans (9). There is no direct evidence suggesting the presence of functional $5-\mathrm{HT}_{4}$ receptors in the gallbladder or biliary tract, and their absence in the sphincter of Oddi has been confirmed (10). Cisapride, a 5-HT 4 -agonist/5-HT $-\mathrm{HT}_{3}$-antagonist, has been variably reported to increase, decrease, and have no effect on gallbladder volume in human subjects (11-13). In animals, cisapride appears to relax the sphincter of Oddi (14). However, its effects on this sphincter in humans have not been reported $(15,16)$. It is possible that the plasma concentration of hormones that can modulate gallbladder contraction may be affected by a promotile agent, for example, tegaserod, secondary to enhanced gastric emptying and acceleration of small intestinal transport (17). Although the effects of tegaserod on gastrointestinal motility have been extensively evaluated in healthy subjects and patients with IBS-C, its potential effect on biliary motility has not been previously studied.

The principal aim of this study, therefore, was to determine the effects of tegaserod on biliary motility as manifested by gallbladder volume and concomitant changes in luminal diameters of the common hepatic duct (CHD) and common bile duct (CBD) (acting as surrogate markers for the functional status of the sphincter of Oddi). Using real-time ultrasonography, serial measurements of gallbladder volume and bile duct diameter before and during meal-induced gallbladder contraction were made during tegaserod and placebo treatment in healthy female subjects and female patients with IBS-C.

\section{SUBJECTS AND METHODS}

\section{Study Design}

This double-blind, placebo-controlled study evaluated the effects of tegaserod on gallbladder contractility and concomitant changes in luminal diameters of the CHD and CBD during gallbladder contraction. A 1-wk baseline screening period without study medication was followed by two 2-wk crossover periods, which involved administration of tegaserod or placebo, separated by a 1-wk washout period

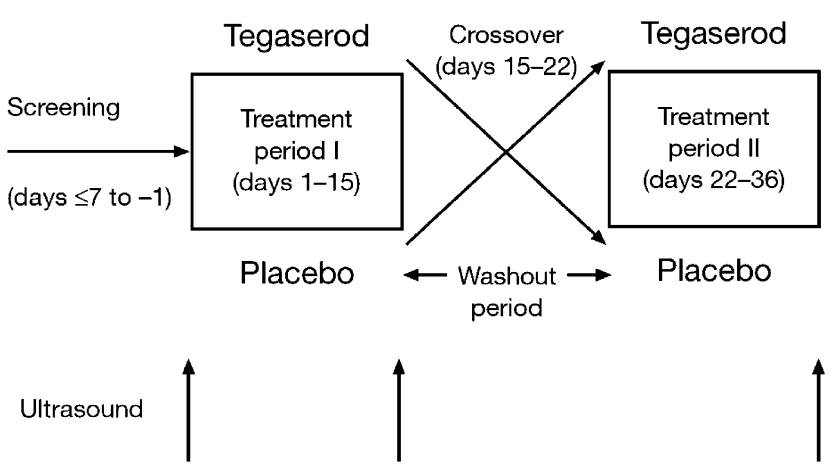

Figure 1. Study design.

(Fig. 1). Gallbladder volumes and concomitant change in luminal diameter of the CHD and CBD during the fasting and postprandial periods were assessed serially using real-time ultrasonography at baseline, and again after each of the two 2-wk drug treatment periods.

\section{Study Population}

This study was conducted at six academic centers in the United States following protocol approval by the Institutional Review Board at each participating site. All subjects gave written, informed consent before entering the study. Healthy female subjects and female patients aged 18-60 yr old with an established diagnosis of IBS-C were enrolled. Gallbladder and biliary structural evaluations were conducted using ultrasound to rule out the presence of gallstones, biliary sludge, gallbladder wall thickening, CHD and CBD dilation $(\geq 7 \mathrm{~mm}$ in diameter), and any other apparent biliary pathology. All subjects had normal liver function tests. Morbid obesity (body mass index (BMI) >34) was a criterion for exclusion. All medications known to affect biliary or gastrointestinal motility, including erythromycin, somatostatin, ondansetron, morphine, and others, were prohibited. Tegaserod $6 \mathrm{mg}$ b.i.d., the recommended dose for patients with IBS-C, was evaluated in 13 healthy female subjects (cohort I) and 20 female patients with IBS-C (cohort II); tegaserod $12 \mathrm{mg}$ b.i.d. was evaluated in an additional 20 female patients with IBS-C (cohort III). Results from each cohort were analyzed separately.

\section{Study Conduct}

Subjects' suitability for inclusion in this study was assessed during the 1-wk screening period. Eligible subjects were then randomized to receive one of two regimens: $2 \mathrm{wk}$ of tegaserod followed by 2 wk of placebo, or 2 wk of placebo followed by 2 wk of tegaserod (Fig. 1). After a minimum fast of $8 \mathrm{hr}$, all subjects underwent a baseline ultrasound assessment to determine the pretreatment gallbladder volume and CHD and CBD diameters. A commercially available liquid test meal (BoostPlus $^{\text {TM }}: 374 \mathrm{ml}=360 \mathrm{cal}, 14 \mathrm{~g}$ protein, $14 \mathrm{~g}$ fat) was then consumed over $5 \mathrm{~min}$. Repeated ultrasound measurements of gallbladder volume and concomitant diameter of 
the CHD and CBD were conducted every 15 min during the 60 -min period after consumption of the liquid test meal. This assessment of meal-induced gallbladder contraction (decrease in volume) and concomitant internal diameters of CHD and CBD before and during gallbladder emptying was repeated after each of the two 2-wk periods of study drug administration. The last dose of study medication was administered $30 \mathrm{~min}$ after starting the pre-meal ultrasound assessment, and $30 \mathrm{~min}(\mathrm{~T}-30)$ before ingestion of the liquid test meal at time zero $\left(\mathrm{T}_{0}\right)$. Thus, ultrasound assessments were conducted before ingestion of the test meal (i.e., $\mathrm{T}-30$ and $\mathrm{T}_{0}$ ) to evaluate effects of the study medication (tegaserod or placebo) alone on gallbladder emptying and then continued during and after the liquid meal to evaluate the effects of meal stimulation. The investigators assessed patient compliance with the treatment regimen by quantitating the number of unused tablets returned and also questioning the patient.

\section{Blood Sampling for CCK Measurement}

To evaluate whether tegaserod $6 \mathrm{mg}$ b.i.d. changed the postprandial concentration of CCK, serial blood samples for measurement of CCK were collected from subjects in cohorts I and II at 15 and $30 \mathrm{~min}$ before and $30 \mathrm{~min}$ after the test meal, respectively. Concentrations of $\mathrm{CCK}$ were measured using a specific radioimmunoassay (sensitivity $0.8 \mathrm{pmol} / \mathrm{l}$ ) described previously (18).

\section{Ultrasound Assessment of Gallbladder Contractility}

Real-time high-resolution ultrasonography was used to assess meal-stimulated gallbladder emptying (contractility) at 15-min intervals from $45 \mathrm{~min}$ before to $60 \mathrm{~min}$ after, physiological stimulation of gallbladder contraction by the test meal. Gallbladder volume was calculated by an accepted method using the formula for a prolate ellipse (19). For each subject, the following parameters of gallbladder contraction were measured or calculated: (a) fasting gallbladder volume (FV) was established by averaging the two measurements at $\mathrm{T}-45$ and $\mathrm{T}-30$. In addition, a post-tegaserod fasting volume was also calculated at $\mathrm{T}_{0}$ to assess for a stimulating effect of tegaserod alone on gallbladder contraction. Previous PK studies of tegaserod have demonstrated that $\mathrm{C}_{\max }$ usually occurs between 30 and 75 min after oral dosing (20-22); (b) residual volume (RV) was defined as the smallest gallbladder volume achieved within $60 \mathrm{~min}$ after the test meal; (c) maximal emptying volume was calculated as the difference between FV and RV; (d) ejection fraction was expressed as a percentage of FV minus RV divided by FV; (e) ejection rate was calculated by dividing the maximal emptying volume by the time to reach RV; (f) peak ejection rate was the ejection rate during the first $30 \mathrm{~min}$ after the test meal; (g) ejection period was the time required from test meal ingestion to reach the RV. A significant or abnormal change in diameter of the CHD and CBD was defined as dilation of either duct equal to or greater than $2 \mathrm{~mm}$ following the test meal, according to the criteria of Simeone et al. (23).

\section{Ultrasound Assessment of the Luminal Diameter of the $C H D$ and $C B D$}

Measurements of the luminal diameters of the CHD and CBD (proximal and distal) were conducted at the same time that measurements of the gallbladder volume were performed. The internal diameter of the duct, excluding wall thickness, was measured after obtaining a long-axis view of the duct at the specified level. (In all cases there was an attempt to measure duct diameters at three levels: in the porta hepatis within $1 \mathrm{~cm}$ of crossing the hepatic artery, in the mid-portion of the duct, and at the level of entry of the duct into the pancreas.) In the few cases where it was not possible to get an acceptable long-axis view of the duct, particularly at the pancreatic head, the measurement was obtained from the cross-sectional view.

\section{Standardized Procedure and Blinded Central Reading of Ultrasound Measurements}

To minimize interobserver variations associated with realtime ultrasonography, a standardized method for the performance of ultrasound examinations was used at the six participating centers, and prestudy training in the method was conducted. All gallbladder, CHD, and CBD images were recorded on videotape and submitted to one central ultrasound reader for quality confirmation. This single reviewer (P. O'Kane) conducted a blinded reading of ultrasound results centrally at the Thomas Jefferson Medical College Ultrasound Research and Education Institute, Philadelphia.

\section{Recording of Adverse Events}

All adverse events occurring during the study were documented.

\section{Statistics}

An analysis of variance (ANOVA) model was individually fitted for each of the following efficacy variables: fasting gallbladder volume, gallbladder ejection fraction, ejection period, peak ejection rate, ejection rate, RV, and maximal emptying volume. A repeated measure ANOVA model was used for luminal diameters of the bile ducts and the CCK concentration, with the observation time as a repeated factor. The sources of variation in the ANOVA model were sequences (fixed effect with two levels), subjects (random effects nested in sequences), treatments (fixed effect with two levels, tegaserod and placebo), and periods (fixed effect with two levels). Between-treatment comparisons for tegaserod versus placebo were made for the change from baseline. Each statistical test was conducted at the significance level of 0.05 (two-sided).

\section{RESULTS}

Ninety percent or more of the randomized healthy subjects and IBS-C patients completed the study. One healthy female subject discontinued due to diarrhea and three female patients with IBS-C were disqualified due to protocol violations 
Table 1. Subject Characteristics

\begin{tabular}{lccc}
\hline & $\begin{array}{c}\text { Cohort I } \\
\text { Healthy } \\
\text { Subjects } \\
(\mathrm{n}=13)\end{array}$ & $\begin{array}{c}\text { Cohort II } \\
\text { IBS-C } \\
\text { Patients } \\
(\mathrm{n}=20)\end{array}$ & $\begin{array}{c}\text { Cohort III } \\
\text { IBS-C } \\
\text { Patients } \\
(\mathrm{n}=20)\end{array}$ \\
\hline Tegaserod & $6 \mathrm{mg}$ b.i.d. & $6 \mathrm{mg}$ b.i.d. & $12 \mathrm{mg}$ b.i.d. \\
Completed study n (\%) & $12(92)$ & $19(95)$ & $18(90)$ \\
Female (\%) & 100 & 100 & 100 \\
Age in yr (mean) & $21-55(36)$ & $21-51(35)$ & $24-59(42)$ \\
BMI (mean) & $18-25(22)$ & $16-30(23)$ & $19-33(25)$ \\
Mean duration of & NA & 11 & 14 \\
IBS (yr) & & & \\
\hline
\end{tabular}

$\mathrm{NA}=$ not applicable.

(Table 1). Subjects who received a different sequence of study medication in each cohort (i.e., tegaserod followed by placebo or placebo followed by tegaserod) were comparable in terms of age, BMI, and concomitant medications.

\section{Ultrasound Visualization Success Rate}

Bile duct measurements were taken at three visits. At each visit, there were 11 time points at which attempts were made to measure diameter at three distinct areas in the duct. All subjects had measurements taken at all time points and at each portion of the duct during each visit. However, there were three subjects in whom at a single time point, a measurement could not be made at a particular portion of the duct. The rates for visualization failure were $0.18 \%$ for all three bile duct measurements, $5.76 \%$ for distal bile duct measurements, $2.61 \%$ for mid-bile duct measurements, and $0.42 \%$ for proximal bile duct measurements.

\section{Effect of Tegaserod on Gallbladder Contractility}

The effect of tegaserod on gallbladder contractility was analyzed during both the interdigestive (fasting) period and the post-meal digestive (postprandial) period.

\section{EFFECT OF TEGASEROD ON GALLBLADDER CON-} TRACTION DURING THE FASTING PERIOD. To evaluate whether tegaserod alone stimulates gallbladder contraction during the fasting period (before test-meal-induced gallbladder emptying), the fasting gallbladder volume which was obtained before tegaserod administration at $\mathrm{T}-30 \mathrm{~min}$ was compared with that obtained at $\mathrm{T}_{0}$, immediately before test-meal ingestion. Tegaserod did not cause gallbladder contraction during the 30 min following oral administration of the drug in either healthy female subjects or female patients with IBS-C treated with $6 \mathrm{mg}$ b.i.d. or $12 \mathrm{mg}$ b.i.d. compared to placebo (Table 2 and Fig. 2).

EFFECT OF TEGASEROD ON GALLBLADDER CONTRACTILITY PARAMETERS DURING THE POSTPRANDIAL PERIOD. The period of gallbladder emptying was defined as the time from $T_{0}$ when ingestion of the test meal was started, to $60 \mathrm{~min}$ later or when gallbladder emptying was completed, whichever was earlier. After $2 \mathrm{wk}$ of tegaserod treatment, gallbladder contractility parameters
Table 2. Mean Change in Gallbladder Volume 30 Minutes after Tegaserod Administration

\begin{tabular}{|c|c|c|c|}
\hline & $\begin{array}{l}\text { Gallbladder } \\
\text { Volume } \\
\text { Change } \\
\text { (cc/min) } \\
\text { (Tegaserod) }\end{array}$ & $\begin{array}{l}\text { Gallbladder } \\
\text { Volume } \\
\text { Change } \\
\text { (cc/min) } \\
\text { (Placebo) }\end{array}$ & $p$-Value \\
\hline Cohort I & & & \\
\hline $\begin{array}{l}\text { Healthy subjects ( } 6 \mathrm{mg} \text { b.i.d.) } \\
\text { Cohort II }\end{array}$ & +0.06 & +0.02 & 0.601 \\
\hline $\begin{array}{l}\text { IBS-C patients ( } 6 \mathrm{mg} \text { b.i.d.) } \\
\text { Cohort III }\end{array}$ & +0.04 & +0.05 & 0.68 \\
\hline IBS-C patients (12 mg b.i.d.) & +0.09 & +0.04 & 0.486 \\
\hline
\end{tabular}

(ejection fraction, ejection rate, peak ejection rate, ejection period, maximal emptying volume, and RV) remained essentially unchanged and were not statistically significantly different from those observed with placebo or at baseline in all cohorts (Fig. 2 and Table 3).

\section{Effect of Tegaserod on Bile Duct Diameter as a Reflection of Sphincter of Oddi Function}

The functional status of the sphincter of Oddi was assessed indirectly by measuring the changes in the luminal diameter of the CHD and the CBD (proximal and distal) using highresolution real-time ultrasonography. These measurements were acquired, along with gallbladder volume measurements, every $15 \mathrm{~min}$ from $45 \mathrm{~min}$ before, to $60 \mathrm{~min}$ after, the test meal. Two weeks of administration of tegaserod had no significant effect on luminal diameters of the CHD and the CBD during both the fasting period and the meal-induced gallbladder emptying period compared to placebo (Table 4). These findings suggest that tegaserod does not cause increased resistance by the sphincter of Oddi to impede flow of bile from the duct into the duodenum. Inspection of data plots from individual subjects showed no evidence for significant dilation of the CHD and the CBD during the test-meal-induced gallbladder emptying, i.e., no absolute diameter of $\geq 7 \mathrm{~mm}$ (upper limit of normal) was observed, and there was no increase in luminal diameter over the pre-meal value, which exceeded $2 \mathrm{~mm}$.

\section{Effect of Tegaserod on Plasma Concentration of CCK}

Plasma concentration of CCK was measured at $30 \mathrm{~min}$ before, and 15 and $30 \mathrm{~min}$ after the test meal. Tegaserod $6 \mathrm{mg}$ b.i.d. did not alter the normal increase in plasma CCK concentration that occurred in response to the test meal in healthy female subjects or female patients with IBS-C treated with placebo (Table 5).

\section{Safety and Tolerability}

Tegaserod was well tolerated by both healthy female subjects and female patients with IBS-C. No serious or unexpected adverse events were reported for any subjects in the three cohorts during periods of outpatient administration of both placebo and tegaserod. Additionally, no major complaints, 

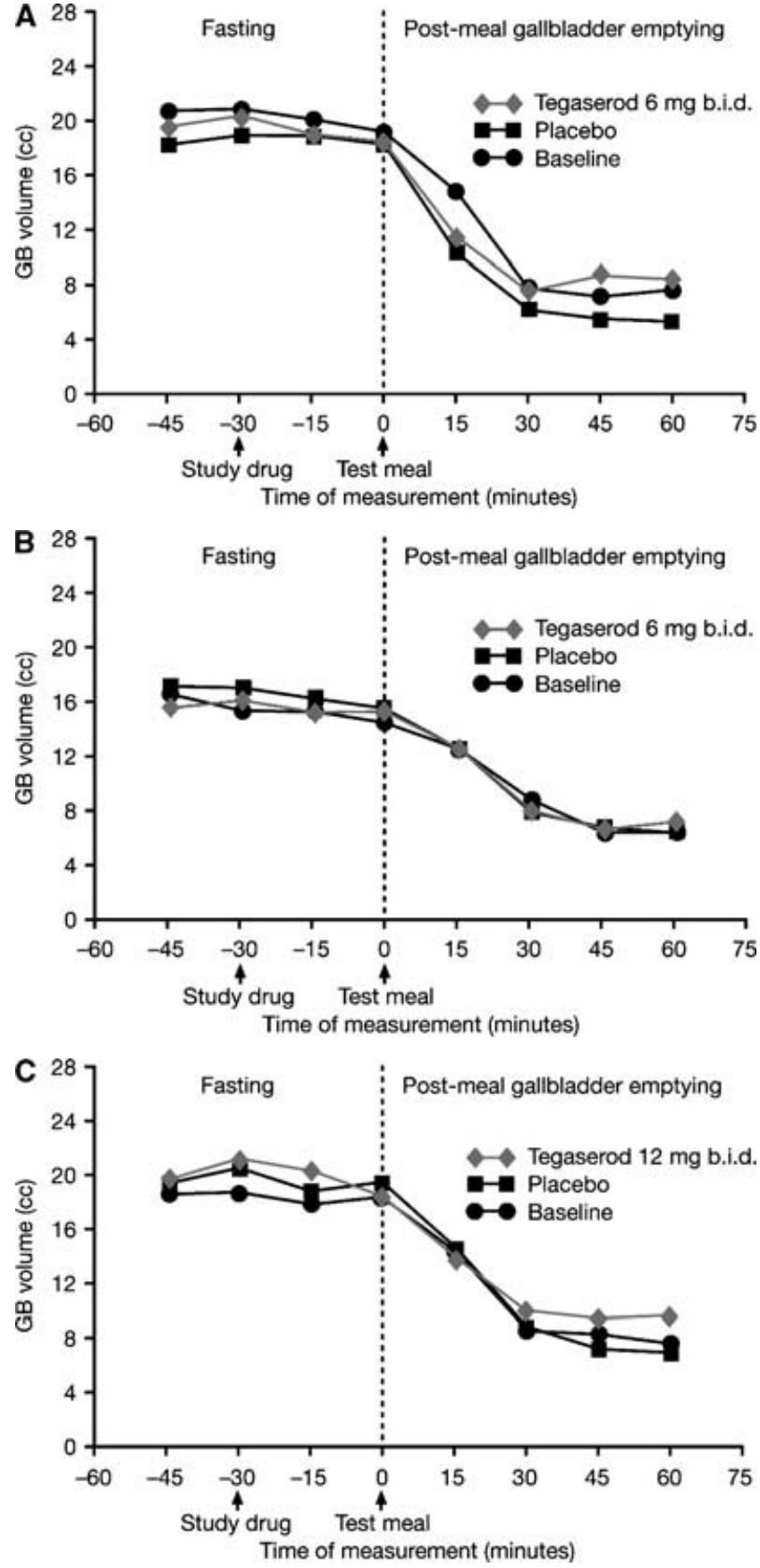

Figure 2. (A) Fasting gallbladder volumes and test-meal-induced gallbladder emptying in healthy female subjects receiving tegaserod $6 \mathrm{mg}$ b.i.d. or placebo. (B) Fasting gallbladder volumes and testmeal-induced gallbladder emptying in female IBS-C patients receiving tegaserod $6 \mathrm{mg}$ b.i.d. or placebo. $(C)$ Fasting gallbladder volumes and test-meal-induced gallbladder emptying in female IBS-C patients receiving tegaserod $12 \mathrm{mg}$ b.i.d. or placebo.

in particular abdominal pain, were reported during the ultrasound test meal evaluation.

\section{DISCUSSION}

In contrast to the promotile effects of tegaserod, a pure 5-HT 4 agonist, on the stomach, small intestine, and colon, this study demonstrates that tegaserod administration does not initiate gallbladder contraction during the fasting period, has no effect on meal-induced gallbladder contractility dynamics, and does not appear to induce contraction of the sphincter of Oddi sufficient to cause resistance to bile flow into the duodenum as reflected by bile duct diameter during maximum meal-stimulated bile flow. Fasting and postprandial plasma CCK concentrations in healthy female subjects and in female patients with IBS-C also were not affected by tegaserod.

The study used real-time high resolution ultrasonography to directly evaluate for any effect of tegaserod on gallbladder contractility and to indirectly assess any effect of tegaserod on resistance to bile flow at the sphincter of Oddi as reflected by an increase in the luminal diameters of the CHD and CBD during maximal bile flow associated with mealinduced gallbladder contraction. Previous studies have shown that real-time ultrasonography is an accurate and reproducible noninvasive method for measuring gallbladder volume and contraction (24). Although the "gold standard" for evaluation of the functional status of the sphincter of Oddi is endoscopic retrograde cholangiopancreatography (ERCP) with sphincter of Oddi manometry (25), these procedures are invasive and can be associated with a significant incidence of acute pancreatitis $(23,26)$. Therefore, it was not considered appropriate to utilize ERCP or sphincter of Oddi manometry in these study subjects with no history of biliary disease. In addition, repeated post-meal evaluations were required by the study protocol. An increase in bile duct diameter assessed by ultrasound during the peak bile flow, which accompanies meal-induced gallbladder contraction, has been reported in cases of partial obstruction of the distal bile duct $(27,28)$.

An excellent rate of visualization of the gallbladder and bile ducts sufficient for the required measurements was achieved in this study and is attributed to the following factors: (a) The scanning was performed by highly experienced investigators who were the same at each measurement session and who were aware that imaging the bile duct was critical to the study. (b) The same patients were scanned first at baseline and then repeatedly during drug treatment. Thus, any difficulties in defining certain anatomical areas were known in advance of the ultrasound sessions conducted during drug treatment. (c) The most modern equipment available in 2002, including image magnification, was used. The advances in imaging technology contributed to obtaining better results than possible in previous years. (d) Severe obesity, which can impair image quality, was part of the exclusion criteria and thus not a problem in this study. All of these four factors contributed to a high degree of adequate bile duct segment visualization permitting measurement of diameter.

Both obesity and pregnancy have been reported to be associated with increased fasting gallbladder volume and decreased postprandial gallbladder contraction $(29,30)$. Therefore, subjects with morbid obesity (i.e., BMI > 34), or who were pregnant, were excluded from this study. There have been conflicting reports about the effect of the menstrual 
Table 3. Gallbladder Contractility Variables after 2 Weeks' Treatment with Tegaserod or Placebo

\begin{tabular}{|c|c|c|c|c|}
\hline & Baseline & Tegaserod (6 mg b.i.d.) & Placebo & $p$-Value \\
\hline \multicolumn{5}{|c|}{ Cohort I: Healthy female subjects $(\mathrm{n}=12 /$ group) } \\
\hline Ejection fraction $(\%)$ & $72(18)$ & $69(25)$ & $77(19)$ & 0.253 \\
\hline Ejection rate (cc/min) & $0.37(0.2)$ & $0.43(0.3)$ & $0.36(0.2)$ & 0.435 \\
\hline Peak ejection rate (cc/min) & $0.38(0.2)$ & $0.38(0.2)$ & $0.41(0.3)$ & 0.435 \\
\hline Ejection period (min) & $45(11)$ & $36(18)$ & $45(14)$ & 0.231 \\
\hline Maximal emptying (cc) & $15(6)$ & $14(6)$ & $15(7)$ & 0.749 \\
\hline Fasting vol. (cc) & $21(6)$ & $20(9)$ & $19(8)$ & 0.613 \\
\hline Residual vol. (cc) & $5.7(4)$ & $6.2(5)$ & $4.0(3)$ & 0.228 \\
\hline \multicolumn{5}{|c|}{ Cohort II: IBS-C patients ( $\mathrm{n}=19 /$ group) } \\
\hline Ejection fraction $(\%)$ & $63(23)$ & $63(17)$ & $67(13)$ & 0.291 \\
\hline Ejection rate (cc/min) & $0.22(0.2)$ & $0.26(0.2)$ & $0.23(0.1)$ & 0.421 \\
\hline Peak ejection rate (cc/min) & $0.19(0.2)$ & $0.25(0.2)$ & $0.26(0.1)$ & 0.971 \\
\hline Ejection period (min) & $55(10)$ & $44(13)$ & $52(10)$ & 0.051 \\
\hline Maximal emptying (cc) & $11(7)$ & $10(6)$ & $11(7)$ & 0.349 \\
\hline Fasting vol. (cc) & $16(8)$ & $16(7)$ & $17(9)$ & 0.404 \\
\hline Residual vol. (cc) & $5.1(3)$ & $5.6(3)$ & $5.6(3)$ & 0.844 \\
\hline \multicolumn{5}{|c|}{ Cohort III: IBS-C patients ( $\mathrm{n}=18$ /group) } \\
\hline Ejection fraction $(\%)$ & $65(17)$ & $62(22)$ & $67(16)$ & 0.159 \\
\hline Ejection rate (cc/min) & $0.28(0.2)$ & $0.30(0.2)$ & $0.29(0.2)$ & 0.982 \\
\hline Peak ejection rate (cc/min) & $0.34(0.2)$ & $0.29(0.2)$ & $0.36(0.3)$ & 0.303 \\
\hline Ejection period (min) & $49(14)$ & $46(12)$ & $52(10)$ & 0.161 \\
\hline Maximal emptying (cc) & $12(6)$ & $12(6)$ & $14(7)$ & 0.418 \\
\hline Fasting vol. (cc) & $19(7)$ & $20(8)$ & $20(9)$ & 0.874 \\
\hline Residual vol. (cc) & $6.4(4)$ & $8.0(6)$ & $6.1(4)$ & 0.091 \\
\hline
\end{tabular}

Values in this table are mean values and standard deviations (SD) are given in parenthesis.

cycle on gallbladder motility. One study reported a small effect, which decreased gallbladder emptying, whereas, others have reported no effects on gallbladder motility $(30,31)$. Accordingly, the phase of the menstrual cycle was not controlled for in this study.

Administration of tegaserod for $2 \mathrm{wk}$ was considered sufficient time to show a pharmacodynamic effect of the drug on gallbladder contraction and to allow for the equilibration of any meal-related factors that may affect biliary motility (e.g., bile acid pool size and secretion of regulatory intestinal peptides). Previous studies evaluating the pharmacodynamic effects of tegaserod on gastrointestinal tract motility have demonstrated an effect after only 1 wk or less. For example, the rate of gastric emptying was increased after only 48 $\mathrm{h}$ of tegaserod treatment (3). The transit of a radionuclidelabeled meal through both the small intestine and colon was accelerated after 3 days of tegaserod treatment (2). Thus, we considered that $2 \mathrm{wk}$ of treatment would be adequate to show any effect of tegaserod on gallbladder contraction, if such develops. Although no effect was observed, by using only the data in this 2-wk treatment study, the possibility that some delayed effect may occur toward the end of the approved treatment period for tegaserod cannot be excluded. However, this seems unlikely.

Both the $6 \mathrm{mg}$ b.i.d. dose of tegaserod currently approved for the treatment of IBS-C and twice this dose, $12 \mathrm{mg}$ b.i.d., were tested. The latter was specifically evaluated to determine if a higher dose of tegaserod might unmask some drug effect

Table 4. Mean Diameters of CHD and CBD after 2 Weeks' Treatment with Tegaserod or Placebo

\begin{tabular}{|c|c|c|c|c|c|}
\hline \multirow[b]{2}{*}{ Duct } & \multicolumn{2}{|c|}{ Tegaserod (6 mg b.i.d.) } & \multicolumn{2}{|c|}{ Placebo } & \multirow[b]{2}{*}{$p$-Value* } \\
\hline & Pre-meal & Post-meal & Pre-meal & Post-meal & \\
\hline \multicolumn{6}{|c|}{ Cohort I: Healthy female subjects $(\mathrm{n}=12)$} \\
\hline CHD (mm) (range) & $2.89(1.2-5)$ & $3.19(1.8-5.2)$ & $3.08(1-5)$ & $3.07(0.8-5.6)$ & 0.799 \\
\hline CBD (mm) Proximal (range) & $3.04(1.3-5.3)$ & $3.19(1.3-6.2)$ & $3.26(1.1-5.7)$ & $3.32(1.3-6)$ & 0.631 \\
\hline CBD (mm) Distal (range) & $2.23(0.9-4)$ & $2.35(1-5.5)$ & $2.71(1.6-4.7)$ & $2.63(1.0-5.1)$ & 0.193 \\
\hline \multicolumn{6}{|l|}{ Cohort II: IBS-C patients $(\mathrm{n}=18)$} \\
\hline CHD (mm) (range) & $2.19(0.6-5)$ & $2.40(0.9-5.3)$ & $2.24(0.1-5.0)$ & $2.29(0.6-5)$ & 0.671 \\
\hline CBD (mm) Proximal (range) & $2.67(0.5-6.5)$ & $2.82(0.6-6.7)$ & $2.67(0.5-6.0)$ & $2.78(0.8-6.0)$ & 0.523 \\
\hline CBD (mm) Distal (range) & $2.16(0.9-3.8)$ & $2.26(1.0-4.2)$ & $2.10(0.5-4.3)$ & $2.20(0.8-4.0)$ & 0.667 \\
\hline \multicolumn{6}{|c|}{ Cohort III: IBS-C patients $(\mathrm{n}=18)$} \\
\hline CHD (mm) (range) & $2.44(0.7-5.7)$ & $2.60(0.8-5.9)$ & $2.64(0.8-5.8)$ & $2.65(0.5-5.2)$ & 0.637 \\
\hline CBD (mm) Proximal (range) & $2.88(1.1-5.4)$ & $3.10(0.8-6.5)$ & $2.91(0.9-5.8)$ & $2.96(0.8-6.8)$ & 0.163 \\
\hline CBD (mm) Distal (range) & $2.63(0.7-5.2)$ & $2.57(0.7-4.7)$ & $2.62(0.9-4.8)$ & $2.67(1.0-4.4)$ & 0.744 \\
\hline
\end{tabular}

Pre-meal: $\mathrm{T}-45$ to $\mathrm{T}=0$; post-meal: $\mathrm{T}+15$ to $\mathrm{T}+60$.

${ }^{*} p$-value is from testing between tegaserod and placebo overall across all the time points. 
Table 5. Plasma CCK Concentration after 2 Weeks' Treatment with Tegaserod (6 mg b.i.d.) or Placebo

\begin{tabular}{lccc}
\hline & \multicolumn{2}{c}{ CCK Concentration (pmol/1) } \\
\cline { 2 - 4 } & $\begin{array}{c}\text { - } 30 \text { Min } \\
\text { Mean (SD) }\end{array}$ & $\begin{array}{c}+15 \text { Min } \\
\text { Mean (SD) }\end{array}$ & $\begin{array}{c}+30 \text { Min } \\
\text { Mean (SD) }\end{array}$ \\
\hline $\begin{array}{l}\text { Cohort I: Healthy female subjects }(\mathrm{n}=12) \\
\quad 0.96(0.43)\end{array}$ & $4.43(3.88)$ & $2.66(1.94)$ \\
$\quad$ Placebo & $0.96(0.37)$ & $5.15(3.60)$ & $3.35(2.65)$ \\
$\quad$ Tegaserod (6 mg b.i.d.) & $0.84(0.16)$ & $2.81(3.31)$ & $1.93(0.62)$ \\
Cohort II: IBS-C patients $(\mathrm{n}=18)$ & $0.83(0.09)$ & $2.05(1.20)$ & $2.31(1.26)$ \\
$\quad$ Placebo & & & 0.438 \\
$\quad$ Tegaserod (6 mg b.i.d.) & & & 0.680 \\
\hline
\end{tabular}

Note: Assay sensitivity $0.8 \mathrm{pmol} / 1$.

${ }^{*} p$-value is from testing between tegaserod and placebo overall across all the time points.

that resulted in increased gallbladder contraction. No change in biliary emptying dynamics was observed. In a previous clinical study, tegaserod at the $12 \mathrm{mg}$ b.i.d. dose had been well tolerated (32). No symptoms suggesting abnormal biliary tract motility were observed at this high dose in either the current or the earlier study.

Results from the present study showed the following: (a) Tegaserod administered during fasting does not stimulate gallbladder contraction as its volume remained unchanged after tegaserod administration. (b) Tegaserod, administered before a meal as recommended, does not alter post-meal gallbladder contractility dynamics, since both the magnitude and rate of emptying remained unchanged after tegaserod treatment compared to baseline or placebo treatment values. (c) Tegaserod did not alter a surrogate marker for increased pressure or resistance at the sphincter of Oddi because the diameters of the CHD and CBD during the period of enhanced bile flow during maximal gallbladder emptying were not significantly increased. (d) Tegaserod did not affect plasma CCK concentration during fasting or during the $60 \mathrm{~min}$ after a test meal compared with placebo. This finding suggests that tegaserod does not interfere with the normal physiological processes that regulate postprandial gallbladder emptying. (e) Tegaserod caused no adverse biliary symptoms during meal-induced stimulation of gallbladder contraction in either healthy subjects or patients with IBS-C.

\section{SUMMARY}

In healthy female subjects and female patients with IBS-C, 2 wk administration of tegaserod does not affect fasting gallbladder volume or stimulate gallbladder contraction during the interdigestive (fasting) period. Tegaserod also does not alter meal-induced (postprandial) dynamics of gallbladder contractility or the diameters of the CHD or CBD measured concomitantly by high-resolution ultrasound as a surrogate marker for sphincter of Oddi function causing resistance to bile flow.

\section{ACKNOWLEDGMENTS}

The authors would like to thank Katherine Hodges and Matthew Joynson from Thomson ACUMED for their editorial contribution to the manuscript.
Reprint requests and correspondence: David L. Earnest, M.D., Novartis Pharmaceuticals Corporation, Clinical Research and Development, One Health Plaza, East Hanover, NJ 079361080. Received March 17, 2003; accepted January 30, 2004.

\section{REFERENCES}

1. Grider JR, Foxx-Orenstein AE, Jin JG. 5-Hydroxytryptamine 4 receptor agonists initiate the peristaltic reflex in human, rat and guinea pig intestine. Gastroenterology 1988; 115:370-80.

2. Prather CM, Camilleri M, Zinsmeister AR, et al. Tegaserod accelerates orocecal transit in patients with constipationpredominant irritable bowel syndrome. Gastroenterology 2000;118:463-8.

3. Degen L, Matzinger D, Merz M, et al. Tegaserod, a 5-HT 4 receptor partial agonist, accelerates gastric emptying and gastrointestinal transit in healthy male subjects. Aliment Pharmacol Ther 2001;15:1745-51.

4. Kennedy TM, Jones RH. Epidemiology of cholecystectomy and irritable bowel syndrome in a UK population. Br J Surg 2000;87:1658-63.

5. van Erpecum KJ, Venneman NG, Portincasa P, et al. Review article: Agents affecting gall-bladder motility — role in treatment and prevention of gallstones. Aliment Pharmacol Ther 2000;14(suppl 2):66-70.

6. Peeters T, Matthijs G, Depoortere I, et al. Erythromycin is a motilin receptor agonist. Am J Physiol Gastrointest Liver Physiol 1989;257:G470-4.

7. Catnach SM, Fairclough PD, Trembath RC, et al. Effect of oral erythromycin on gallbladder motility in normal subjects and subjects with gallstones. Gastroenterology 1992;102:2071-6.

8. Doggrell SA, Scott GW. The occurrence of postsynaptic alpha- and beta-adrenoceptors in the guinea pig gall-bladder. Br J Pharmacol 1980;71:185-9.

9. Sengupta S, Cooney R, Baj M, et al. Prokinetic effect of indoramin, an alpha-adrenergic antagonist on human gallbladder. Aliment Pharmacol Ther 2002;16(10):1801-3.

10. Hillsley K, Mawe GM. 5-HT is present in nerves of guinea pig sphincter of Oddi and depolarizes sphincter of Oddi neurons. Am J Physiol Gastrointest Liver Physiol 1998;275(38):G1018-27.

11. Marzio L, DiGiammarco AM, Capone F, et al. Effect of cisapride on human fasting gallbladder volume: A real-time ultrasonographic study. Eur J Clin Pharmacol 1986;29:6313.

12. Ziegenhagen DJ, Heitz W, Kruis W, et al. Cisapride increases gallbladder volume in gallstone patients before and 
after extracorporeal shock wave lithotripsy. Aliment Pharmacol Ther 1993;7:617-22.

13. Thorens J, Schnegg JF, Brignoli R, et al. Effect of cisapride on gallbladder motility after extracorporeal shockwave lithotripsy. J Hepatol 1995;22:333-7.

14. Baker RA, Saccone GT, Toouli J. Cisapride inhibits motility of the sphincter of Oddi in the Australian possum. Dig Dis Sci 1990;35:711-5.

15. von Kiedrowski R, Huijghebaert S, Raedsch R. Mechanisms of cisapride affecting gallbladder motility. Dig Dis Sci 2001;46:939-44.

16. Patankar R, Ozmen MM, Sanderson A, et al. Effect of cisapride on gallbladder emptying and plasma CCK in normal and vagotomized human subjects. Dig Dis Sci 1996;41:5438.

17. Marzio L. Factors affecting gallbladder motility: Drugs. Dig Liver Dis 2003;35(suppl 3):S17-9.

18. Hopman WP, Kerstens PJ, Jansen JB, et al. Effect of graded physiologic doses of cholecystokinin on gallbladder contraction measured by ultrasonography. Determination of threshold, dose-response relationships and comparison with intraduodenal bilirubin output. Gastroenterology 1985;89:1242-7.

19. Dodds WJ, Groh WJ, Darweesh RM, et al. Sonographic measurement of gallbladder volume. Am J Roentgenol 1985;145:1009-11.

20. Appel-Dingemanse S, Horowitz A, Campestrini J, et al. The pharmacokinetics of the novel promotile drug, tegaserod, are similar in healthy subjects: Male and female, elderly and young. Aliment Pharmacol Ther 2001;15:937-44.

21. Appel-Dingemanse S. Clinical pharmacokinetics of tegaserod, a serotonin 5-HT(4) receptor partial agonist with promotile activity. Clin Pharmacokinet 2002;41:1021-42.

22. Swan SK, Zhou H, Horowitz A, et al. Tegaserod pharmacoki- netics are similar in patients with severe renal insufficiency and healthy subjects. J Clin Pharmacol 2003;43:359-64.

23. Simeone JF, Mueller PR, Ferrucci JT Jr, et al. Sonography of the bile ducts after a fatty meal: an aid in detection of obstruction. Radiology 1982;143:211-5.

24. Sherman S, Lehman GA. Sphincter of Oddi dysfunction: Diagnosis and treatment. JOP 2001;2:382-400.

25. Elbrond H, Huniche B, Ostergaard L, et al. Oddi's sphincter dysfunction. Ugeskr Laeger 1989;151:2507-9.

26. Toouli J. Evaluation of sphincter of Oddi function. Aust N Z J Surg 1989;59:445-8.

27. Fein AB, Rauch RF II, Bowie JD, et al. Intravenous cholecystokinin octapeptide: Its effect on the sonographic appearance of the file ducts in normal subjects. Radiology 1984; 153:499-501.

28. Palasciano G, Serio G, Portincasa P, et al. Gallbladder volume in adults, and relationship to age, sex, body mass index, and gallstones: A sonographic population study. Am J Gastroenterol 1992;87:493-7.

29. Gourtsoyiannis NC, Damilakis JE, Charoulakis NZ, et al. Relationship of gallbladder contour, fasting volume and emptying to body size indices in normal subjects and patients with gallstones. Digestion 1995;56:395-9.

30. Kern F Jr, Everson GT, DeMark B, et al. Biliary lipids, bile acids, and gallbladder function in the human female. Effects of pregnancy and the ovulatory cycle. J Clin Invest 1981;68:1229-42.

31. Xynos E, Haroulakis N, Petrakis I, et al. N. Effect of the menstrual cycle on gallbladder fasting volume and postprandial emptying in nulliparous young females. Invest Radiol 1997;32:330-4.

32. Langaker KJ, Morris D, Pruitt R, et al. The partial 5-HT 4 agonist (HTF 919) improves symptoms in constipation predominant irritable bowel syndrome. Digestion 1998;59:S3. 